\title{
The Effect of Contents for Instruction in Physical Education on Cognitive and Psychomotor Development in Tunisian Students Aged from 9 Until 11 Years
}

\author{
Souhir Ezzedini ${ }^{1}$, Yousri Elghoul ${ }^{1,}$, Fatma Bahri $^{1}$, Liwa Masmoudi ${ }^{1}$, Adene Gharbi ${ }^{1}$, \\ Mohamed Frikha ${ }^{2}$, Nizar Souissi ${ }^{3}$ \\ ${ }^{1}$ High Institute of Sport and Physical Education, Sfax University, Sfax, Tunisia \\ ${ }^{2}$ King Faisal University, Department of Physical Education, Al Hufuf, KSA \\ ${ }^{3}$ National Observatory on Sport, Tunis, Tunisia
}

Email address:

elghoulyousri@yahoo.fr (Y.Elghoul)

${ }^{*}$ Corresponding author

\section{To cite this article:}

Souhir Ezzedini, Yousri Elghoul, Fatma Bahri, Liwa Masmoudi, Adene Gharbi, Mohamed Frikha, Nizar Souissi. The Effect of Contents for Instruction in Physical Education on Cognitive and Psychomotor Development in Tunisian Students Aged from 9 Until 11 Years. International Journal of Sports Science and Physical Education. Vol. 2, No. 2, 2017, pp. 20-28. doi: 10.11648/j.ijsspe.20170202.11

Received: May 18, 2017; Accepted: June 5, 2017; Published: July 18, 2017

\begin{abstract}
The aim of this study was to examine the effect of three months of teaching physical education on cognitive and psychomotor development in 9-11 year-old boys. 48 healthy students of both sexes (Age $=10,8 \pm 0,8$ years; Height $=1,45 \pm 0$, $09 \mathrm{~cm}$; Body mass $=37,9 \pm 9,1 \mathrm{~kg}$ ) performed 4 cognitive tasks: cognitive flexibility (TMT A and B), inhibition (Flanker Test), selective attention (Barrage Test) and reaction time (computer task) and four psychomotor tasks: psychomotor mobilization (Skipping Rope Jump Test), eye-hand coordination (Basketball Wall Pass \& Dart-throwing) and eye-leg coordination (Soccer Ball Wall Volley) were applied in the field and the lab. The sample was divided in three groups: group 1 (10 students), group 2 (22 students) and control group (16 students). The equipment and the measurements were taken immediately before and after three months of physical education program. The contents for instruction in physical education didn't allow an improvement in flanker test in G2. G1 undergone physical education and did physical activities outside of school shows a significant improvement in cognitive flexibility and inhibition. It has brought improvement for the G2 to the level of selective attention. CG has experienced an improvement in the reaction time, it allowed again a development of eye-leg coordination; of eye-arm coordination was determined in CG higher than the tow other groups. A correlation links the cognitive and the psychomotor skills. The results demonstrated that contents for instruction allowed a relative cognitive and psychomotor development, the updating of contents for instruction remains legitimate and urgent given all the changes in Tunisia.
\end{abstract}

Keywords: Physical Education, Physical Activities, Contents for Instruction, Psychomotor Abilities, Cognitive Abilities

\section{Introduction}

Physical education is a field which puts in evidence an approach of the global development of the man, an approach which considers that the spirit and the body are only one entity and all it touches one will have obviousness on the other. Physical teachers estimate that "the child is a unit" that comes to the school to study what requires a mental and physical formation. Thus, the physical and mental process has a particular importance in the school system [1]. They provide a regular and structured participation physical- activity [2]. The world is worried about the lack of physical activity among children [3]; this inactivity is considered the fourth leading cause of mortality worldwide [4]. There is a general lack of awareness of the importance of the potential contribution of physical education as a mechanism to increase physical activity and therefore improve overall health and academic performance [5], according to study [6], structured physical education is important for psychomotor development in preschool children. The benefits of physical 
activity in children are well-documented [7]; it is beneficial for their health and essentially at the cognitive level [7-8]. Cognitive and psychomotor development in children are a very important topic in the field of scientific research; they represent the basis of learning [9-10]; as well as the two processes are correlates in a classroom [11], a recent reviews showed again a positive relations between physical education and academic achievement such as study [12].

The choice of the present study was due to several reasons; the examination of the specificity of the learning of children at the age of 9 to 11 years is essential to understand the learning processes as a theoretical object. The first years (6 to 12 years) of the child's school age are characterized by the transition to primary school in which the child learns [13]. A many recent studies encourage young researchers to measure motor and cognitive abilities, and to unravel the processes responsible for motor performance, motor coordination, executive functions and visio-spatial competences in children which are strongly linked academic achievement; become more important and still remain a topic research [10].

The literature examines the relationship between physical activity and cognitive function and focuses primarily on older populations [14]. The psychomotor current broke with the standard conceptions of learning and established a new description of learning which focus on cognitive and motor phases [15]. The study [16] put in evidence the importance and the need of an active intervention in physical education sessions because physical education is the only program that provides moderate and vigorous physical activity that it represents the public health priority [5].

Based on these facts, this study aimed (i) to study the effect of physical education on cognitive development (selective attention and reaction time) and on the development of executive functions (cognitive flexibility and inhibition). (ii) To study the effect of physical education on psychomotor development (eye-hand coordination, eye-leg and psychomotor mobilization). (iii) To Study the relationship between the different parameters (cognitive and psychomotor functions).

\section{Methods}

\subsection{Participants}

A total of 48 right-handed and typically developing children aged 9-11 volunteered to participate in this study. The study was conducted according to the Ethic Committee of the National Centre of Medicine and Science of Sports of Tunis; most children came from similar socioeconomic backgrounds. The sample is composed of three groups. Group $1(\mathrm{G} 1)$ : they practice physical education at school (2 sessions per week for 1 hour session), and they have outside school physical activities ( 3 sessions per week for 1 hour and half in their civilian teams), group 2 (G2): they practice only physical education at school (2 sessions per week for 1 hour session), control group (CG): They did not have any physical activities at school and outside school. The students have no previous experience of the tasks they were asked to perform.

\subsection{Procedures}

Subjects performed a battery of psychomotor and cognitive tests in two experimental sessions separated by three months. They were divided in 2 groups; the time that the first one did cognitive assessment the second one did the psychomotor assessment. The score of the tests in which students used papers and pencils, was calculated when the papers were corrected. After each computer task, the score was automatically recorded and the score of the psychomotor tests was directly recorded too after every attempt.

\subsection{Cognitive Assessment}

Cognitive flexibility represents the ability of changing attention and switching rapidly between response and the Trail Making Test (TMT) is the way to measure it

Trail Making Test (TMT) is a task that needs a paper and pencil and it contains two parts. In Trail Making part A, the subject must connect circles in numerical order $(1,2,3 \ldots)$, while in part $B$ the subject must alternate between the two order numerical and alphabetical (i.e. 1-A-2-B-3-C, etc.), The subject must draw a line from one point to the next as quickly as possible [17]. Each part of this test needs three minutes. The TMT measures visual and visuo-motor abilities. TMT part $\mathrm{A}$ is seen as measuring a visual search, motor function and attention, whereas TMT part B purportedly a measure of executive functions, visual search, speed of attention, and motor function [18-19-20]. The measures of both tasks included the time of completion and number of errors committed [20].

Inhibition is the Ability to Control Attention by Focusing on One Task While Inhibiting Other Stimuli [21]. The task of Flanker Erikson is one of the most used tests to measure inhibitory control in children. It requires selective attention; the child identifies the direction of the arrow in a central position (eg $<<<<=$ congruent or $<<<<>>>>$ not congruent) as quickly and accurately as possible. The subject responds by the direction opposite to the direction of the arrow presented in the centre and reacts very slowly because of the need to exercise control [22].

The reaction time is a task that the subject realizes with the computer, as previously described by the studies [23-24] the subject has a colored geometric shape (the target). With the appearance of the target, he must click on the button in the computer, and it will automatically calculate the speed of the reaction. Each subject had 20 targets presented, the score is calculated in (ms) and the highest score reflects the poorest performance.

Selective attention is the ability to focus on one task to the detriment of other tasks [25]. It is measured through the barrage test. The barrage test is a selection measure of visual negligence with a rapid visualization of the spatial distribution of the targets and their quantification to visual negligence the subject must circle all the targets (bells). A 
total of 35 targets (bells) were distributed equally in seven columns. In each column, there was the same number of targets. All symbols are in black, the evaluation includes the number of crossed and unbarred bells it test lasts 3 minutes and the best performance corresponds to the higher number of crossed bells [26].

\subsection{Psychomotor Assessment}

Skipping Rope Jump Test is a psychometric task which measure Psychomotor Mobilization that lasts 30 seconds [2728-29]. The score will be the number of cycles performed.

Basketball Wall Pass is a task which measures eye-hand coordination. It consists of bouncing the ball against the wall with both hands, the distance against the wall and the height of the ball are adequate for the capabilities of the subject. The performance is the number of passes during the 30 second. The game ends automatically when the subject loses the ball [27- 28-29].

Soccer Ball Wall Volley is a task which measures eye-leg coordination. It consists of bouncing the ball against the wall with the leg. The distance to the wall and the height of the ball are adequate for the capabilities of the subject the performance and number of passes during the 20s. The game ends automatically when the subject loses the ball [27-2829].

Dart-throwing is a task which Subject performed a dartthrowing test in two experimental sessions, after each dart throw the score was recorded [30] and then the dart was collected for the next throw. An official dart was placed on a wall so that its centre was at eye level for each subject. Participants threw six darts [31] after a familiarization session [32]. From two different distances: $2 \mathrm{~m}$ (SD) and $2.37 \mathrm{~m}$ (LD) [33]; that were marked by a line on the floor. The students' posture and the technique of throwing of darts were chosen by the participants themselves. However, they remain the same during the various trials [30]. Measurements were taken immediately before and after 3 months of physical education. The physical education session is composed of three parts: The first part of the session lasts 15 minutes which composed of general and specific warming up it consists of (jumps, passes and games with the ball, dynamic and static stretches...). A second part of 40 minutes deals with physical activities from a sporting point of view. During this part, 2 to 3 learning situations are proposed that have been based on sports activities. These situations are in line with the operational objective of the session and the specific objective of the activity in question. The activities proposed are collective sport (football, basketball and volleyball). The teachers of the courses have the same level of expertise ( 8 to 10 years) in order to minimize any effect on learning.

Before starting the experiment, the subjects became familiar with the experimental equipment (the computer, the darts, the paper and the pencil, the balls and the rope) to guarantee a good reproducibility of the results of the different experiments tests. All subjects were evaluated by tests and measurements taken before and after three months of training.

\section{Statistical Methods}

All statistical tests were processed using STATISTICA Software (StatSoft, Paris, France). The results were expressed by the mean \pm standard deviation. The normality of the distribution was verified by the chapiro-wilk test and all variables were verified by Gauss's normal distribution. After the normality check, the parametric tests were realized. The analysis of the data was performed by ANOVA analysis of two factors. 3 groups (G1, G2, and CG) realized 2 measurements (repeated; before vs after). If the variables were significant, a post hoc test was applied. A correlation was applied to identify the relationship between the various variables. The probability threshold is set to $\mathrm{p}<0.05$.

\section{Results}

\subsection{Cognitive Performance}

For the time TMT part, the mean and standard deviation showed that the results of the post-test are significantly lower than the pre-test values in G1, a significant inter-group difference between $C G$ and G1; the values of the pre-test are significantly lower in the CG. G1 showed an improvement in the time spent during the TMT task (part A) (table 1).

A positive correlation was observed in the G1 between the TMT time (part A) and the congruent time of the Flanker test $(\mathrm{r}=0.7, \mathrm{p}<0.05)$ and also between the time variable and the congruent time of the test Flanker $(r=0.43, p<0.05)$. Similarly, a positive correlation was observed in the CG between the time variable and the mean reaction time $(\mathrm{r}=$ $0.5, \mathrm{p}<0.05)$. A positive correlation links the three groups together to the time level and errors committed TMT (part A) $(\mathrm{r}=0.62 ; \mathrm{p}<0.001)$; A positive correlation between the time of the TMT test (part A) and the congruent time of the flanker test $(r=0.44 ; p<0.01)$ and between the time of the TMT test (part A) and the time average of reaction $(\mathrm{r}=0.3, \mathrm{p}$ $<0.05)$.

For the committed errors TMT (part A); a significant intragroup difference (G1) whose number of errors committed is significantly lower compared to the pre-test (table1). In the G1 the TMT errors committed (part A) are positively correlated to the congruent time of the Flanker test $(r=0.76$, $\mathrm{p}<0.05)$ and to the average reaction time $(\mathrm{R}=0.76, \mathrm{p}<0.05)$. In the three groups together a significant correlation correlates the errors committed in TMT (part A) to the congruent time of the Flanker test $(r=0.37, p<0.05)$.

For the Corrected errors TMT (part A) the corrected errors variable was noticed include some correlations; in the G1 a positive correlation with the non-congruent time of Flanker test $(r=0.71, p<0.05)$. In the $\mathrm{CG}$, corrected errors are negatively correlated to the Skipping Rope Jump Test $(\mathrm{r}=$ $0.77, \mathrm{p}<0.01)$; which gives a correlation between the cognitive and psychomotor processes. Finally, a positive correlation in the three groups together that correlates the corrected errors to the time non-congruent of Flanker test $(\mathrm{r}=$ $0.31, \mathrm{p}<0.05)$.

About the Time TMT (part B) the result showed a 
significant intra-group difference (G1, G2 \& CG) was determined; the post-test mean values were significantly lower than the pre-test values. The three groups recognized a development, but the best improvement was recorded in the G1 with a difference percentage of $(-33 \%)$ (table 1$)$. The time variable TMT (part B) was noticed include some correlations: in the G1 a positive correlations with the crossed bells of the barrage test was determined $(r=0.64, p$ $<0.05$ ), a negative correlation with unbarred bells ( $\mathrm{r}=-0.64$, $\mathrm{p}<0.05)$. And a negative correlation with the Basket ball pass $(\mathrm{r}=-0.68, \mathrm{p}<0.05)$.

For the errors committed TMT part, B; a significant difference intra-group in the three groups, values are significantly lower than those of the pre-test and more specifically in the $\mathrm{G} 2$ with a difference percentage of (74.3\%). A significant inter-group difference G2 and CG concerning post-test which $\mathrm{G} 2$ regressed than the $\mathrm{CG}$ in the number of errors committed (table 1). The errors committed TMT (part B) was noticed include some correlations: In the $\mathrm{G} 1$ it is correlated to the number of errors of the reaction time test $(\mathrm{r}=0.65, \mathrm{p}<0.05)$ and a negative correlation with the dart-throwing test D2 $(r=-0.77, p<0.01)$. In the G2, it is negatively correlated to the test of the Soccer Ball Wall Volley $(-0.43, p<0.05)$ and in the three groups, there is a negative correlation with the crossed bells of the barrage test $(-0.32 ; \mathrm{p}<0.05)$.

For the corrected errors TMT (part B); the corrected errors have some correlations: in the G2 it correlates with the crossed bells $(\mathrm{r}=0.66, \mathrm{p}<0.01)$; A positive correlation with the crossed bells $(\mathrm{r}=0.54, \mathrm{p}<0.001)$ and a positive correlation with the Basket Ball Pass $(r=0.31, p<0.05)$.

The results showed again in the congruent time variable of
Flanker test a significant intra-group difference in CG and G1. The post-test values are lower than those of the pre-test with a better improvement in the G1 with a difference percentage of $(-36.2 \%)$; A reduction in the time spent by the subjects (table 1). The congruent time is correlated to some variables: In the G1; it is positively correlated to the average reaction time $(\mathrm{r}=0.77, \mathrm{p}<0.01)$, and is negatively correlated to Basket Ball Pass Test ( $\mathrm{r}=-0.64 \mathrm{P}<0.05)$; In the $\mathrm{G} 2$ it is also negatively correlated to the percentage of success of the same task too $(\mathrm{r}=-0.6, \mathrm{p}<0.01)$. In the $\mathrm{CG}$, it is positively correlated to the Skipping Rope Jump Test $(r=-0.64$, $p$ $<0.05$ ); and in the three groups it is negatively correlated to the percent of success $(r=-0.3, p<0.05)$.

For the incongruent time, the post-test values are significantly lower than the pre-test level in G1 which put in evidence the role played by extracurricular activity in improving inhibitory control in children (table1). Incongruent time is negatively correlated with the percentage of success in the $\mathrm{G} 1(\mathrm{r}=-0.71, \mathrm{p}<0.05)$.

Finally percent of success, the percent of success is correlated to certain variables: In the $\mathrm{G} 2$, it is positively correlated to the dart-throwing distance $1(\mathrm{r}=0.48, \mathrm{p}<0.05)$; in the $\mathrm{CG}$, it is positively correlated to the number of errors reaction time $(\mathrm{r}=0.8, \mathrm{p}<0.001)$.

For unbarred balls of barrage test a significant inter-group difference (G1 and G2) was determined, which the level of visual negligence is initially higher in G2 than G1 included. The post-test values in G2 are lower than the pre-test (table 1). In the $\mathrm{G} 2$, the unbarred bells are positively correlated to the congruent time of Flanker Test $(r=0.45, p<0.05)$. In the CG the unbarred bells are negatively correlated to the congruent time of Flanker test $(\mathrm{r}=-0.54, \mathrm{p}<0.05)$.

Table 1. Means, standard deviation and delta change of cognitive abilities in the pre-test and post-test for the three groups (G1 \& G2 \& CG); ( $=48)$.

\begin{tabular}{|c|c|c|c|c|}
\hline \multicolumn{2}{|l|}{ Variables } & G1 & G2 & \multirow{2}{*}{$\frac{\text { CG }}{49,7 \pm 10,8 \#}$} \\
\hline Time TMT & Before & $70,4 \pm 45,2$ & $55,2 \pm 30,5$ & \\
\hline part A & After & $46 \pm 8,6^{*}$ & $45,8 \pm 26,8$ & $35 \pm 9,2$ \\
\hline & $\Delta(\Delta \%)$ & $-24,4(-34,7 \%)$ & $-9,4(-17,1 \%)$ & $-14,7(-29,6 \%)$ \\
\hline \multirow[t]{2}{*}{ TMT part A } & After & $0 \pm 0$ * & $0 \pm 0,2$ & $0 \pm 0$ \\
\hline & $\Delta(\Delta \%)$ & $-0,8(-100 \%)$ & $0(0 \%)$ & $0(0 \%)$ \\
\hline Corrected errors & Before & $0,1 \pm 0,3$ & $0 \pm 0$ & $0,1 \pm 0,3$ \\
\hline TMT part & $\Delta(\Delta \%)$ & $0(0 \%)$ & $0(0 \%)$ & $0(0 \%)$ \\
\hline \multirow[t]{3}{*}{ Time TMT part B } & Before & $70,4 \pm 45,2$ & $55.2 \pm 30.5$ & $49.7 \pm 10.8 \#$ \\
\hline & After & $46 \pm 8,6^{*}$ & $45,8 \pm 26,8$ & $35 \pm 9,2$ \\
\hline & $\Delta(\Delta \%)$ & $-24,4(-34,7 \%)$ & $-9,4(-17,1 \%)$ & $-14,7(-29,6 \%)$ \\
\hline Committed errors & Before & $8,3 \pm 5,5$ & $8,7 \pm 6,4$ & $9,3 \pm 6,9$ \\
\hline \multirow[t]{2}{*}{ TMT part B } & After & $4 \pm 4,3^{*}$ & $2,2 \pm 3,8^{*}$ & $5,9 \pm 5,7 * \$$ \\
\hline & $\Delta(\Delta \%)$ & $-4,3(-51,8 \%)$ & $-6,5(-74,3 \%)$ & $-3,4(-36,5 \%)$ \\
\hline Corrected errors & Before & $0,3 \pm 0,7$ & $0,3 \pm 1,1$ & $0 \pm 0$ \\
\hline TMT part B & $\Delta(\Delta \%)$ & $-0,2(-66,7 \%)$ & $-0,1(-28,6 \%)$ & $0,2(0 \%)$ \\
\hline \multirow[t]{3}{*}{ Crossed bells } & Before & $30,6 \pm 1,7$ & $28 \pm 4,7$ & $31,8 \pm 2,2 \$$ \\
\hline & After & $31,5 \pm 2,3$ & $27,9 \pm 8,3$ & $30,6 \pm 3,1$ \\
\hline & $\Delta(\Delta \%)$ & $0,9(2,9 \%)$ & $-0,2(-0,6 \%)$ & $-1,2(-3,7 \%)$ \\
\hline \multirow[t]{3}{*}{ Unbared bells } & Before & $4,4 \pm 1,7$ & $7 \pm 4,7 \#$ & $3,2 \pm 2,2 \$$ \\
\hline & After & $3,5 \pm 2,3$ & $4,4 \pm 3,7^{*}$ & $3,1 \pm 2,5$ \\
\hline & $\Delta(\Delta \%)$ & $-0,9(-20,5 \%)$ & $-2,5(-36,6 \%)$ & $-0,1(-2 \%)$ \\
\hline \multirow[t]{3}{*}{ Congruent time } & Before & $1297,9 \pm 497,3$ & $1133,1 \pm 517,9$ & $1296,4 \pm 647,9$ \\
\hline & After & $828,1 \pm 259,9 *$ & $983,5 \pm 258,9$ & $833 \pm 292,5^{*}$ \\
\hline & $\Delta(\Delta \%)$ & $-469,8(-36,2 \%)$ & $-149,6(-13,2 \%)$ & $-463,4(-35,7 \%)$ \\
\hline
\end{tabular}




\begin{tabular}{|c|c|c|c|c|}
\hline Variables & & G1 & G2 & CG \\
\hline \multirow{3}{*}{ Incongruent time } & Before & $1609,7 \pm 1284,9$ & $1485,3 \pm 633,1$ & $1401,4 \pm 621,5$ \\
\hline & After & $981,5 \pm 287,3 *$ & $1178,7 \pm 506,9$ & $1051 \pm 483,7$ \\
\hline & $\Delta(\Delta \%)$ & $-628,3(-39 \%)$ & $-306,7(-20,6 \%)$ & $-350,4(-25 \%)$ \\
\hline Percent of & Before & $91,5 \pm 18,1$ & $92,7 \pm 8,7$ & $97,2 \pm 8,8$ \\
\hline \multirow[t]{2}{*}{ Successes } & After & $94 \pm 6,6$ & $95,5 \pm 11,1$ & $93,8 \pm 12$ \\
\hline & $\Delta(\Delta \%)$ & $2,5(2,7 \%)$ & $2,7(2,9 \%)$ & $-3,4(-3,5 \%)$ \\
\hline \multirow{3}{*}{$\begin{array}{l}\text { The average of } \\
\text { reaction time }\end{array}$} & Before & $672,1 \pm 164,7$ & $661,9 \pm 182,2$ & $787,1 \pm 298,6$ \\
\hline & After & $626,7 \pm 229$ & $587,2 \pm 189,3$ & $695,1 \pm 146,2$ \\
\hline & $\Delta(\Delta \%)$ & $-45,4(-6,8 \%)$ & $-74,7(-11,3 \%)$ & $-92(-11,7 \%)$ \\
\hline \multirow{3}{*}{$\begin{array}{l}\text { Errors } \\
\text { time }\end{array}$} & Before & $0,5 \pm 0,7$ & $0,3 \pm 0,6$ & $1,3 \pm 2,1 \$$ \\
\hline & After & $0.4 \pm 0.7$ & $0.4 \pm 0.6$ & $0 \pm 0^{*}$ \\
\hline & $\Delta(\Delta \%)$ & $-0,1(-20 \%)$ & $0(14,3 \%)$ & $-1,3(-100 \%) \# \$$ \\
\hline
\end{tabular}

*: Significant difference compared to pre-test at $\mathrm{p}<0,05$.

\#: Significant difference compared to G1 at $\mathrm{p}<0,05$.

$\$$ : Significant difference compared to G1 at G2 at $\mathrm{p}<0,05$.

\subsection{Psychomotor Performance}

For the Skipping Rope Jump test a significant difference was determined; there is a development in the number of cycles performed during the $30 \mathrm{sec}$ in G2 (table 2). The Skipping Rope Jump Test is correlated to some variables: in the G1 it is positively correlated to the Soccer Ball Wall Volley Test $(\mathrm{r}=0,77, \mathrm{p}<0,01)$; in the $\mathrm{G} 2$ it is negatively correlated to weight $(\mathrm{r}=-0.53, \mathrm{p}<0.05)$; in the three groups together it is also positively correlated to in the three groups together it is also positively correlated to Soccer Ball Wall Volley Test $(\mathrm{r}=0.44, \mathrm{p}<0.01)$ and correlated negatively to weight $(\mathrm{r}=-0.31 ; \mathrm{P}<0.05)$.

For the Soccer Ball Wall Volley test a significant intragroup difference was determined (G1 \& G2), a difference significantly greater than the pre-test with a better improvement in the G2 with a difference percent of $(190.5 \%)$ and a significant inter-group difference (G2), (CG) and (G1) (table 2).

For the Basket ball pass test in the CG a difference significantly greater than the post-test level compared to the pre-test was observed, the finding showed the existence of a significant inter-group difference. The $\mathrm{CG}$ is the most developed group in this skill, unlike the other two groups in physical education (table 2).

Finally, for the Dart-throwing test a significant inter-group difference G2 values are significantly lower than G1 \& CG in dart-throwing D2, while, any significant difference in the test dart-throwing D1 (table 2).

Table 2. Means, standard deviation and delta change of psychomotor abilities in the pre-test and post-test for the three groups (G1 \& G2 \&CG); (N=48).

\begin{tabular}{lllll}
\hline Variables & & G1 & G2 & CG \\
\hline Skipping rope & Before & $10,9 \pm 11,3$ & $8,8 \pm 9,3$ & $11,4 \pm 11,5$ \\
jump test & After & $14,6 \pm 9$ & $12,8 \pm 8,1 *$ & $8,9 \pm 10,8$ \\
& $\Delta(\Delta \%)$ & $3,7(33,9 \%)$ & $4(44,8 \%)$ & $-2,5(-22 \%) \# \$$ \\
Soccer Ball & Before & $1,8 \pm 2,4$ & $1 \pm 0,8$ & $1,3 \pm 0,5$ \\
Wall Volley & After & $4,1 \pm 2,4 *$ & $2,8 \pm 2^{*} \#$ & $1,8 \pm 0,9 \# \$$ \\
& $\Delta(\Delta \%)$ & $2,3(127,8 \%)$ & $1,8(190,5 \%)$ & $0,4(33,3 \%)$ \\
Basket ball pass & Before & $20,7 \pm 8,9$ & $16,8 \pm 9,9$ & $11,4 \pm 11,5$ \\
& After & $16,6 \pm 10$ & $2,8 \pm 2 * \#$ & $2,2 \pm 10,5 *$ \\
Dart-throwing D1 & $\Delta(\Delta \%)$ & $-4,1(-19,8 \%)$ & $3,1(18,4 \%)$ & $12,3(138,7 \%) \# \$$ \\
& Before & $3,4 \pm 1,6$ & $3,4 \pm 1,7$ & $2,4 \pm 2,6$ \\
Dart-throwing D2 & After & $2,5 \pm 1,4$ & $2,6 \pm 1,5$ & $2,9 \pm 2,2$ \\
& $\Delta(\Delta \%)$ & $-0,9(-26,8 \%)$ & $-0,8(-23,1 \%)$ & $0,5(20,4 \%)$ \\
& Before & $3,4 \pm 1,3$ & $2,2 \pm 1,8$ & $2,8 \pm 2,3$ \\
\hline
\end{tabular}

*: Significant difference compared to pre-test at $\mathrm{p}<0,05$.

\#: Significant difference compared to G1 at $\mathrm{p}<0,05$.

\$: Significant difference compared to $\mathrm{G} 1$ at $\mathrm{G} 2$ at $\mathrm{p}<0,05$.

D1: distance 1.

D2: distance 2 .

\section{Discussion}

\subsection{The Effect of Physical Education on Cognitive Development (Cognitive Flexibility, Inhibition, Reaction Time and Selective Attention)}

The results have shown that physical activity allowed the development of cognitive flexibility is consistent with some studies [34-35]. The contents for instruction in physical education didn't allow an improvement in flanker test in G2. However, G1 were undergone physical education and outside school activities showed a significant improvement in congruent time, non-congruent time and TMT (part A). The discussion of this idea is very limited in the literature. This 
result does not line up with previous studies that have shown cognitive flexibility development in a group that makes physical education despite being categorized as the third executive function based on cognitive inhibition [36-37]. This could be explained by the inefficiency of the content in the physical education sessions or the goals pursued. Thus, there is an association between physical activity and cognitive performance [38-39-40-41-42-43].

Although the results are not significant, a variety of explanations can be considered; the way in which physical activity is manipulated varies in form, intensity and duration. The form varies according to the cycles, depending on the training programs; intensity is generally defined as the maximum percent of individual burden and duration is defined by two types of physical activity interventions: shortterm and long-term [40-44-45].

Physical education has brought improvement for the G2 to the level of selective attention this has been developed by a decrease in the number of unbarred bells in the completion of the task which reflects a decrease in neglect visual disorders, visio-spatial disorders and attention-related spatial disorders. In this case, this study partly confirms the hypothesis about the effect of the contents for instruction in physical education on selective attention. This confirms the finding in an earlier study in children aged 8-9 years who participated in 9 months of physical activity and had an improvement in the attention task [46].

The content didn't allow the development of the reaction time whereas the CG has experienced an improvement which is manifested in the reduction of the numbers of errors during the execution of the task computer. Indeed, the idea according to the study [47] considers that daily physical activities can also have effects on cognition.

However, some studies have found contradictory evidence regarding the link between physical activity and cognition [48], this evidence may be due to the fact that academic performance is arbitrarily assessed by academic and cognitive measures [45], according to the proposed conceptualization [48] cognitive performance is mainly related to psycho-physiological evaluation in cerebral function. Physiological mechanisms have been proposed to link physical activity and executive functions; these mechanisms imply a certain threshold of activation of the physiological processes and allowed the improvement of the executive function [40]. The study [49] found that motor coordination was significantly associated to attention and performance in a TMT task, a task that involves cognitive control as well as the working memory outcome which showed that there is a positive correlation between time and errors corrected in TMT (part B) and barred bells in the G1. The executive functions are essential for tasks with a high level of difficulty. In order for the student to manage a change imposed by a task, executive functions play a key role in correcting and adjusting motor programs, allowing mental change of ideas by taking time to think before reacting to concentration tasks away from all automatic actions [21-50]. The results confirm those of [10-51] who consider that new learning requires the executive functions that help children focus, change attention, manipulating information and inhibiting any responses not suited to the objectives.

\subsection{The Effect of Physical Education on Psychomotor Mobilization and Fine Coordination (Eye-Hand and Eye-Leg)}

Children who do more physical education showed acceleration in their psychomotor development which could provide an accelerated academic learning mechanism [52]. Three months of physical education didn't allow the performance of darts-throwing. The practice of dart-throwing is a very sensitive strategy for synchronization errors; position and angular variability are a limiting factor of coordination, the existence of a correlation between the position of the darts and the position of the hand at the release of the darts [53]. Difficulties in coordination are manifested in temporal anomalies between the processing of information and the execution of the motor act, errors in the non-synchronization of individual movements, control errors (inversions or substitutions of movements) or Commutative errors (persevering with previous movement, interference between movements) [54].

In view of the result of the reaction time, the period of three months of physical education didn't improve the reaction time. There is a logical explanation for the non-significance of the results of the eye-hand and eye-leg coordination on the one hand, and motor actions are in agreement with the requirements of the environment, the level of coordination of movements is influenced by disruptive factors. The difficulties of coordination are manifested in the temporal differences between the processing of information and the execution of the motor act, accuracy and speed, and on the other hand, motor coordination is a complex attitude which relies on other psychomotor attitudes [54], which opens up perspectives on the consideration of other aspects of psychomotor development.

The motors and cognitive abilities are the responsible processes for motor performance, motor coordination, executive functions, and visio-spatial skills that are strongly related to academic results [10]. These finding can be interpreted as an additional evidence for an impact of individual's abilities to control coding and selection of responses in all new situations [55]. There are also tests on developing children indicate that motor performance and executive functions have several common underlying processes that are related to planning, monitoring, detecting and correcting errors. All The processes involve long-term planning, response inhibition and working memory [56- 4957-58-55]. A finding that agrees with the negative correlation found in the present study in the G2 between committed errors TMT (part B) and the Soccer Ball Wall Volley.

The study [58] reports a significant relationship between motor performance and inhibition of response. Thus, the idea of [59], which established an overlap between motor coordination and executive functions, resulting in important 
practical implications, the implication of the shared mechanisms, underlies the relationship between these areas including possible involvement of the cerebral function?

In the past, motor and cognitive development have been studied and discussed separately in most cases, but today there is a growing consensus that these two concepts can be fundamentally interdependent [60]. The study [49] found that motor capacity varies according to the speed of task execution and there is an overlap between the processes that are affected in children with motor coordination or attention problems as manifested in the correlations are as following: a negative correlation between the Basketball Wall Pass Test and the selective attention and the correlation between the number of error times of the reaction time test and dartthrowing distance 2 .

\subsection{The Update of Contents for Instruction Is the Solution}

Updating of contents for instruction remains legitimate and urgent given the political and scientific changes in Tunisia; taking the example of the case of physical education in France: Programs of physical education which are based mainly on sporting activities are a factor in the inequalities in terms of success, which is explained by little consideration for differences between pupils at the social and gender level. In the year 1960, an increase in inequalities was noticed because of the importance given to the knowledge to be taught and to the tools in the education of young people [61]. The contents for instruction in Tunisia are based on the different sports activities (team sports and individual sports); the type of sport exercised by the subject also contributes to psychomotor performance; the subjects who practice combat sports (e.g karate or taekwondo) are better than subjects who practice team sports (e.g handball and football) in terms of creativity and psychomotor coordination, better psychomotor coordination [54].

In Germany, [62] have noticed that playing racquet sports in schools (e.g softball, badminton, cricket and baseball, curling...) have a general capacity to lead to invasion; to improve tactics and it creates solutions. In general, conceptual approaches to teaching games related to sport in schools are always about "what to do" and "how to do" in complex game situations: The "what" Type allow the exploration of complex and easily recyclable tactics; the "how" of type questions embrace discussions of methodological principles for teaching tactical skills and the attempt to empirically validate and ensure effectiveness and sustainability in physical education [63]. Physical and psychomotor skills can be developed in situations of high intensity displacement occurring in games [64]. A contemporary thinking in public health argues that physical activity can influence childhood health as well as throughout life, stresses the importance of a lifestyle based on regular physical activity during childhood and adolescence which continues into adulthood [65], perhaps it is time to introduce new physical activities, one may also note the example of American schools; they are the leaders to tackle the challenges of public health.

\section{Conclusion}

This study demonstrated that the effectiveness of physical education program on cognitive and psychomotor development is relative by comparing with the group that were undergone physical education and outside school activities and the control group. Therefore, the updating of contents for instruction remains legitimate and urgent given all the political and scientific changes in Tunisia. Moreover, a correlation links the cognitive and psychomotor skills was established.

\section{Perspectives}

In view of the results, the perspectives are more focused on experiments that seek to find other explanations complementary to these observations. The first perspective would be to evaluate the effects of time of day on students learning, and a second perspective would be to study the effect of regulation (related to the interventions of the teacher and the interactions with learners) on the improvement of the cognitive functions and the psychomotor skills (effectiveness of the regulations).

\section{References}

[1] Sibley, B. A. \& Etnier, J. L. (2003). The relationship between physical activity and cognition in children: a meta-analysis. Pediatric exercise science, 15(3), 243-256.

[2] Zeigler, E. F. (1994). Physical education's 13 principal principles. Journal of Physical Education, Recreation \& Dance, 65(7), 4-5.

[3] Tremblay, M. S., Gray, C. E., Akinroye, K., et al. (2014) Physical activity of children: A global matrix of grades comparing 15 countries. Journal of Physical Activity and Health 11(1): 113-125

[4] Kohl 3rd, H. W., Craig, C. L., Lambert, E. V., Inoue, S., Alkandari, J. R., Leetongin, G., \& Kahlmeier, S. (2012). The pandemic of physical inactivity: global action for public health. The Lancet, 380, 294-305.

[5] Sallis, J. F., McKenzie, T. L., Beets, M. W., Beighle, A., Erwin, H., \& Lee, S. (2012) Physical education's role in public health: Steps forward and backward over 20 years and HOPE for the future. Research Quarterly for Exercise and Sport, 83, 125-135.

[6] Teixeira Costa, H. J., Abelairas-Gomez, C., Arufe-Giráldez, V., Pazos-Couto, J. M., \& Barcala-Furelos, R. (2015). Influence of a physical education plan on psychomotor development profiles of preschool children.

[7] Lee, W., Huang, C., Wu, C., Huang, S., \& Chen, G. (2012). The effects of using embodied interactions to improve learning performance. In 2012 IEEE 12th international conference on advanced learning technologies (ICALT), July 4-6, 2012 (pp. 557e559).

[8] World Health Organization (WHO) (2010). Global recommendations on physical activity for health. World Health Organisation. Geneva. 
[9] Simons-Morton, B. G. (1994). Implementing health-related physical education. In Pate, R. R. and Hohn, R. C. (eds), Health and Fitness Through Physical Education. Human Kinetics, Champaign, IL, pp. 137-146.

[10] Cameron, C. E., Cottone, E. A., Murrah, W. M., \& Grissmer, D. W. (2016). How Are Motor Skills Linked to Children's School Performance and Academic Achievement? Child Development Perspectives.

[11] Becker, D. R., Miao, A., Duncan, R. \& McClelland, M. M. (2014). Behavioral self-regulation and executive function both predict visuomotor skills and early academic achievement. Early Childhood Research Quarterly, 29, 411-424. DOI: 10.1016/j.ecresq.2014.04.014.

[12] Budde, H., Voelcker-Rehage, C., Pietraßyk-Kendziorra, S., Ribeiro, P., \& Tidow, G., (2008). Acute coordinative exercise improves attentional performance in adolescents. Neuroscience Letters. 441(2), pp. 219-223.

[13] Fréchette, N. (2011). Le développement global de l'enfant de 6 à 12 ans en contextes éducatifs. PUQ.

[14] Angevaren M, Aufdemkampe G, Verhaar HJ et al. Physical activity and enhanced fitness to improve cognitive function in older people withoutknown cognitive impairment. Cochrane Database Syst Rev 2008; http://dx.doi.org/10.1002/14651858.CD005381.pub2.

[15] Delignières, D. (1991). Risque perçu et apprentissage moteur. In J. P. Famose, P. Fleurance \& Y. Touchard, Apprentissage moteur et représentations (pp. 157-171). Paris: EPS.

[16] McKenzie, T. L., Sallis, J. F., Prochaska, J. J., Conway, T. L., Marshall, S. J., \& Rosengard, P. (2004). Evaluation of a twoyear.

[17] Reitan RM. Trail making test results for normal and braindamaged children. Percept Mot Skills 1971; 33(2): 575-581.

[18] Lezak, M. D., Howieson, D. B., \& Loring, D. W. (1995). Executive functions and motor performance. Neuropsychological assessment, 3, 650-685.

[19] Mitrushina MN, Boone KB, Razani J, D'Elia LF. 2005. Handbook of normative data for neuropsychological assessment. New York (NY): Oxford University Press.

[20] Strauss E, Sherman EM, Spreen O. 2006. A compendium of neuropsychological tests: administration, norms, and commentary. New York, NY: Oxford University Press.

[21] Diamond A. Executive functions. Annu Rev Psychol, 2013; 64: $135-168$.

[22] Eriksen, B. A., \& Eriksen, C. W. (1974). Effects of noise letters upon the identification of a target letter in a nonsearch task. Perception and Psychophysics, 16, 143-149.

[23] Jarraya M, Jarraya S, Chtourou H, Souissi N. 2012. The effect of the partial sleep deprivation on the reaction time and the attentionnel capacities of the handball's goalkeeper. Biol Rhythm Res. 44: 503-510.

[24] Jarraya, S., Jarraya, M., Souissi, N. (2014). Diurnal variations of cognitive performances in Tunisian children. Biol Rhythm Res. 45: 61-67.

[25] AUBERT, E. (2000). Évaluation des troubles de l'attention de l'enfant à l'adolescent. Evolutions psychomotrices, (50), 208213.
[26] Gauthier L, Dehaut F, Joanette Y. 1989. The bells test: a quantitative and qualitative test for visual neglect. Int J Clin Neuropsychol. 2: 49-54.

[27] Dutta. S. (2014). Comparative study of psychomotor abilities of athletes in relation to sex and area, innovative thoughts international research journal pissn 2321-5143 eissn 23475722 volume 2 , issue 3 .

[28] Dutta. S. (2015). Comparative Study of Psychomotor Abilities of Female Players in Relation to Area and Level of Participation, Asian Resonance P: ISSN NO. 0976-8602 RNI NO. UPENG/2012/42622; VOL.-IV, ISSUE-IV.

[29] Dutta. S, Singh. A. (2013). A comparative study of psychomotor abilities of school and university level athletes, international journal of behavioral social and movement sciences (issn: 2277-7547).

[30] Edwards B, Waterhouse J. 2009. Effects of one night of partial sleep deprivation upon diurnal rhythms of accuracy and consistency in throwing darts. Chronobiol Int. 26: 756-768.

[31] Koyuncu M. 2011. Broadbent's cognitive approach and its effect on motor performance in sports. Psychology. 02: 472-476.

[32] Edwards B, Waterhouse J, Atkinson G, Reilly T. 2007. Effects of time of day and distance upon accuracy and consistenc y of throwing darts. J Sports Sci. 25: 1531-1538.

[33] Emanuel M, Jarus T, Bart O. 2008. Effect of focus of attention and age on motor acquisition, retention and transfer: a randomized trial. Phys Ther. 88: 251-260.

[34] Anderson P. Assessment and development of executive function (EF) during childhood. Child Neuropsychol 2002; 8(2): 71-82.

[35] Diamond A, Lee K. Interventions shown to aid executive function development in children 4 to 12 years old. Science 2011; 333(6045): 959-964.

[36] Davidson, M. C., Amso, D., Anderson, L. C., \& Diamond, A. (2006). Development of cognitive control and executive functions from 4 to 13 years: Evidence from manipulations of memory, inhibition, and task switching. Neuropsychologia, 44(11), 2037-2078.

[37] Garon N, Bryson SE, Smith IM. Executive function in preschoolers: a review using an integrative framework. Psychol. Bull. 2008; 134: 31-60.[PubMed: 18193994].

[38] Kamijo K, Khan NA, Pontifex MB et al. The relation of adiposity to cognitivecontrol and scholastic achievement in preadolescent children. Obesity 2012; 20(12): 2406-2411.

[39] Tomporowski P. Cognitive and behavioral responses to acute exercise in youths: A review. Pediatr Exerc Sci 2003; 15(4): 348-359.

[40] Barenberg, J., Berse, T., \& Dutke, S. (2011). Executive functions in learning processes: do they benefit from physical activity? Educational Research Review, 6(3), 208-222.

[41] Ruiz, JR. Moreno, LA. Ortega, F. B. \& al. Physical activity, fitness, weight status, and cognitive performance in adolescents. J Pediatr 2010; 157(6): 917-922, e5.

[42] Singh. A, Uijtdewilligen, L. Twisk, J. et al. Physical Activity and performance at school a systematic review of the literature including a methodological quality assessment. Arch Pediatr Adolesc Med 2012; 166(1): 49-55. 
[43] Coe D, Pivarnik J, Womack $\mathrm{C}$ et al. Effect of physical education and activity levels on academic achievement in children. Med Sci Sports Exerc 2006; 38(8): 1515-1519.

[44] Westcott, W. L., Winett, R. A., Annesi, J. J., Wojcik, J. R., Anderson, E. S., \& Madden, P. J. (2009). Prescribing physical activity: applying the ACSM protocols for exercise type, intensity, and duration across 3 training frequencies. The Physician and sportsmedicine, 37(2), 51-58.

[45] Esteban-Cornejo, I., Tejero-Gonzalez, C. M., Sallis, J. F., \& Veiga, O. L. (2015). Physical activity and cognition in adolescents: A systematic review. Journal of Science and Medicine in Sport, 18(5), 534-539.

[46] Chaddock-Heyman, L., Erickson, K. I., Voss, M., Knecht, A., Pontifex, M. B., Castelli, D. \& Kramer, A. (2013). The effects of physical activity on functional MRI activation associated with cognitive control in children: a randomized controlled intervention. Frontiers in human neuroscience, 7, 72.

[47] Padilla, C. Pérez, L. \& Andrés, P. (2014). Chronic exercise keeps working memory and inhibitory capacities fit. Frontiers in behavioral neuroscience, 8,49 .

[48] Keeley TJH, Fox KR. The impact of physical activity and fitness on academic achievement and cognitive performance in children. Sport Exerc Psychol 2009; 2(2): 198-214.

[49] Piek JP, Dyck MJ, Nieman A, Anderson M, Hay D, Smith LM, McCoy M, Hallmayer J. 2004. The relationship between motor coordination, executive functioning and attention in school aged children. Arch Clin Neuropsychol. 19: 10631076 .

[50] Elghoul, Y., Frikha, M., Masmoudi, L., Chtourou, H., Chaouachi, A., Chamari, K., \& Souissi, N. (2014). Diurnal variation of cognitive performance and perceived difficulty in dart-throwing performance in 9-10-year-old boys. Biological Rhythm Research, 45(5), 789-801.

[51] Blair, C., Protzko, J., \& Ursache, A. (2011). Self-regulation and the development of early literacy. In Guilford Press.

[52] Roy J. Shephard. (1997). Curricular Physical Activity and Academic Performance, Human Kinetics Publishers, Inc, 9, 113-126.

[53] Hore, J., Watts, S., \& Tweed, D. (1996). Errors in the control of joint rotations associated with inaccuracies in overarm throws. Journal of Neurophysiology, 75(3), 1013-1025.
[54] Vasilica Grigorea, Radu Predoiub, Georgeta Mitrachec. Study Concerning The Psycho-Motor Coordination - Differences Between Sports. Procedia - Social and Behavioral Sciences 30 (2011) $1995-2000$.

[55] Roebers CM, Kauer M. 2009. Motor and cognitive control in a normative sample of 7-year-olds. Dev Sci. 12: 175-181.

[56] Sergeant J. 2000. The cognitive-energetic model: an empirical approach to attention-deficit hyperactivity disorder. Neurosci Biobehavioral Rev. 24: 7-12.

[57] Wassenberg R, Kessels AG, Kalff AC, Hurks PM, Jolles J, Feron FJ, Hendriksen JG, Kroes M, Beeren M, Vles JS. (2005). Relation between cognitive and motor performance in 5- to 6-year-old children: results from a large-scale crosssectional study. Child Dev. 76: 1092-1103.

[58] Livesey D, Keen J, Rouse J, White F. 2006. The relationship between measures of executive function, motor performance and externalizing behaviour in 5- and 6-year-old children. Human Movement Sci. 25: 50-64.

[59] Rigoli, D., Piek, J. P., Kane, R., \& Oosterlaan, J. (2012). An examination of the relationship between motor coordination and executive functions in adolescents. Developmental Medicine \& Child Neurology, 54(11), 1025-1031.

[60] Diamond A. 2000. Close interrelation of motor development and cognitive development and of the cerebellum and prefrontal cortex. Child Dev. 71: 44-56.

[61] Attali, M., \& Saint-Martin, J. (2012). Le sport: Concours commun des IEP. Editions Sedes.

[62] Memmert, D. (2015). Teaching tactical creativity in team and racket sports: Research and practice. Routledge.

[63] Griffin, L. L., Mitchell, S. A., \& Oslin, J. L. (1997). Teaching sport concepts and skills: A tactical games approach. Champaign, IL: Human 835 Kinetics.

[64] Konig, S. (2014a). 'Killing two birds with one stone'—on the effectiveness of implicit training processes in physical education. International Journal of Physical Education, 15, $15-28$.

[65] Malina, R. M. (2001). Physical activity and fitness: pathways from childhood to adulthood. American Journal of Human Biology, 13(2), 162-172. 